\title{
The Essential Ingredients of a Future Curriculum Design
}

\author{
Regina Joseph Cyril \\ Ministry of Education, Malaysia
}

\section{How to cite}

Joseph Cyril, R. (2020). The Essential Ingredients of a Future Curriculum Design. Asia Pacific Journal on Curriculum Studies, 3(1), 10-21. https://doi.org/10.53420/apjcs.2020.3

\begin{abstract}
The advent of industrialization and the advancement of technology at a rapid rate has been a concern for countries that aim to meet the demands of globalization and future job markets. The stability of a country's economy is the aspiration of politicians as opposed to equipping individuals with survival skills to live in a sustainable world as human beings capable of solving problems. What are the essential ingredients for our future generation? The curriculum should produce individuals who can solve problems in the future regardless of the circumstances or a generation equipped with knowledge for future jobs, which are non-existent now. The targeted product should be a human being who is able to balance the demands of modernization through knowledge of artificial intelligence or a holistic individual who can balance mind and matter to thrive in a sustainable world for the common good of our planet and its citizens. This paper attempts to study the right ingredients needed for a future curriculum design by examining what is lacking now and recommending a design suited for sustainable economic and ecological living.
\end{abstract}

Keywords: solve problems, sustainable, balance, holistic, demands

\section{Introduction}

The world is moving at a rapid pace, with industrialization and globalization as well as coping with global warming. As countries try to strike a balance to keep the equilibrium of what is needed for each country, it is an arduous task for policy makers to project the type of future generations which each country wants to produce. This is systematically done through a school curriculum developed in line with the needs of the country, the social strata of the society and the dilemmas enveloping the country.

Today, the world is preparing itself with the changes that may become our lifestyle with the advent of the $4 \mathrm{t} h$ industrial revolution. According to Klaus Schwab, Founder and Executive Chairman of the World Economic Forum, "we stand on a brink of a technological revolution that will fundamentally alter the way we live, work, and relate to one another." Yet, in at another paradigm, the world needs to be able to breathe in order to survive another millennium ; , sustainable development is much needed in a choking world for our future generations. With the work of advocacy towards this endeavour, countries need to work towards sustainable and strategic policies for the future. Yet, each country faces social ills that hamper s its society through various means that can be alarming and need s to be addressed. Policy makers and government officials are hard at work to curb these as well as educate the society for a better future. The scenarios mentioned above will be taken into consideration in the systemic development of the curriculum. What is the balance that we should have for a future curriculum? How do curriculum developers decide on the ingredients of the future curriculum of a country?

The world is going through a rapid change, which we have not experienced before. In order to sustain the planet, our future generations need to be empowered to work collaboratively in order to live and enjoy the common good of the earth. As it is clearly stated by OECD, “....abandon the notion that resources are limitless and are there to be exploited; they will need to value common prosperity, sustainability and well-being. They will need to be responsible and empowered, placing collaboration above division, and sustainability above short-term gain." How do we prepare our children for an increasingly volatile, uncertain, complex and ambiguous world? Preparing our students for the real world, will essentially be helpful for them and the soft skills that will always be useful are curiosity and imagination, initiative and entrepreneurship, agility and adaptability, critical thinking and problem solving, effective oral and written communication, collaboration across networks and leading by influence, as well as accessing and analysing information (Nichols, 2019). 
In a world already embarking on digital technology, which gives access to information at one's fingertips, are rote learning and memorization of concepts essential for our future generation as we have calculators and machines to tabulate the data we want? Should not curriculum developers find means and ways to balance knowledge acquisition with expertise in acquiring information and using soft skills to determine the relevant data needed for a particular intended purpose? Is this the reality of education today, which will make learning relevant for our future generation? Furthermore, the curriculum in Malaysia, has a clear emphasis on 21s t century skills and higher-order thinking skills in order to prepare our students for the future. Many aspects have to be deliberated by curriculum developers in order to produce a curriculum suitable and engaging to pupils from all walks of life, the privileged as well as the deprived, to make learning meaningful, engaging and fun.

\section{Literature Review}

The curriculum of the future essentially needs to go through a thinking process of how to find a balance with the needs of the mid and late $21 \mathrm{~s}$ t century and a generation equipped to live sustainably. Our world is changing at a rapid pace with technological advancement and the notion that countries need to prepare its future generations for jobs that do not exist today is frightening and demanding at the same time. The industrial revolutions experienced by the world from 1784 have brought about great changes in our societies. Each revolution has brought advancements in the way we live, a rise in socio-economic status and modernization. We are today in the cusp of the fourth industrial revolution and as it is very aptly pointed out, "The 4th Industrial Revolution will change not only what we do but also who we are. It will affect our identity and all the issues associated with it: our sense of privacy, our notions of ownership, our consumption patterns, the time we devote to work and leisure, and how we develop our careers, cultivate our skills, meet people, and nurture relationships." (Schwab, 2016) "Propelled by technological breakthroughs, the world is described less and less through historical epochs that last decades. More and more, it is described through 'revolutions' of unparalleled velocity and unknown transformative power. At the start of this century, the technology and information revolution was all the rage. By the second decade, the "industrial revolution' had taken over.... The lag time between each revolution is shrinking, while the complexity between one and the next grows exponentially" (Marope, 2017).

Even more, there is a need for curriculum developers to have a broad foresight to study the implications needed for change. "Curriculum can be understood as a political agreement, policy and technical agreement that reflects the desired type of society considering local, national and global expectations and needs." (IBE Resource Pack, 2018) The desired society is somewhat determined by the needs of the country, the type of citizens a country would like to produce and the global scenario. OECD's learning framework 2030 clearly stipulates that they are "committed to helping every learner develop as a whole person, fulfil his or her potential and help shape a shared future built on the well-being of individuals, communities and the planet." (OECD, 2018) It further reiterates that countries need to educate children "to abandon the notion that resources are limitless and are there to be exploited; they will need to value common prosperity, sustainability and well-being. They will need to be responsible and empowered, placing collaboration above division, and sustainability above short-term gain. In the face of an increasingly volatile, uncertain, complex and ambiguous world, education can make the difference as to whether people embrace the challenges they are confronted with or whether they are defeated by them. And in an era characterized by a new explosion of scientific knowledge and a growing array of complex societal problems, it is appropriate that curricula should continue to evolve, perhaps in radical ways." (OECD, 2018).

The Education 2030 agenda mooted by United Nations Educational, Scientific and Cultural Organization (UNESCO) together with United Nations Children's Fund (UNICEF), the World Bank, United Nations Population Fund (UNPF), United Nations Development Programme (UNDP), UN Women and United Nations High Commissioner for Refugees (UNHCR organized the World Education Forum in 2015 to set a new vision for education. During the forum, Irina Bokova, Director-General of UNESCO pointed out very poignantly that the world community is making a huge step forward, "It reflects our determination to ensure that all children, young people and adults gain the knowledge and skills they need to live in dignity, to fulfil their potential and contribute to their societies as responsible global citizens. It encourages governments to provide learning opportunities through life, so that people can continue to grow and be on the right side of change. It affirms that education, a fundamental human right, is the key to global peace and sustainable development" (Bokova, 2015).

As such, there is a need to plan for broader education goals as never seen before. How do we create responsible global citizens who take on the right side of change. Education for the future needs to take on a giant step of providing a broader set of knowledge, skills, attitudes and values which can equip every child with the necessary attributes are needed for the future. According to OECD, "the rapid advance of science and technology may widen inequities, exacerbate social fragmentation and accelerate resource depletion." And today, with the advancement of science and technology, we are more aware of well-being which is "related to quality of life, including health and this gives rise to civic engagement, social connections, education, security, life satisfaction and the environment" (OECD, 2018). 
In light of this, what is the right ingredient needed for a country in today's situation? The students we are preparing today need to act as agents of change in the future armed with decision-making skills and a reflective mind, able to analyse and anticipate the short and long-term consequences of their actions. The right ingredient will depend on these factors; the current situation in a country in terms of societal norms and, social ills eroding the population and the future that a country aspires to achieve.

Therefore, we need to equip students with the right competencies. Why competency? "It involves the mobilisation of knowledge, skills, attitudes and values to meet complex demands; future-ready students will need both broad and specialised knowledge." (OECD, 2018) As such, students should not only be equipped with knowledge and skills but also with the right competency to exercise the knowledge and skills learnt, i.e. to use their knowledge, skills, attitudes and values to meet the complex demands of the future world. According to OECD, the competencies needed are disciplinary knowledge, epistemic knowledge and procedural knowledge to give every student broad and specialised knowledge and skills to meet the demands of the future. "Disciplinary knowledge...the raw material from which new knowledge is developed, together with the capacity to think across the boundaries of disciplines and "connect the dots". Epistemic knowledge is knowledge about disciplines...enabling students to extend their disciplinary knowledge. Procedural knowledge is acquired by understanding how something is done or made - the series of steps or actions taken to accomplish a goal. Some are domain specific while others are transferable across domains. Students will need to apply their knowledge and skills in unknown and evolving circumstances. For this, they will need a broad range of skills, including cognitive and meta-cognitive skills...; social and emotional skills....; and practical and physical skills..." (OECD, 2018) We will need to equip our students with attitudes and values in order to mediate these broader range of knowledge and skills learnt. "The attitudes and values can be observed at personal, local, societal and global levels. While human lives are is enriched by the diversity of values and attitudes arising from different cultural perspectives and personality traits, there are some human values (e.g. respect for life and human dignity, and respect for the environment) that cannot be compromised." (OECD, 2018).

In order to acquire the previously mentioned knowledge, skills, values and attitudes for future citizens to be able to connect what they have learnt in school and apply it in their lives, all students will need soft skills that enable them to function in a society. Seven survival skills required for the 21 st century, as uncovered by Tony Wagner of Harvard University by interviewing hundreds of CEOs in business, non-profit organisations and educational institutions are : critical thinking and problem solving, collaboration across networks and leading by influence, agility and adaptability, initiative and entrepreneurship, effective oral and written communication, accessing and analysing information, and curiosity and imagination.

The responsibility of curriculum developers is heavy, as they need to be curious, explorative and reflective, in their quest to find the right ingredient for their children. In order to do this, it is important to understand the past and study how existing trends will shape human society by keeping a close watch on the happenings in the world and reflect if these changes will affect the country in the future. The key trends shaping society today, as reported by UNESCO, are: increasing cultural differences, globalisation, increasing gender equity, advances in biotechnology, religious revival, rising environmental concern, increasing poverty , and technology. Education is a wide and diverse field which needs to take into account concerns of various bodies which includes the future of the planet, our home. The Earth Charter, an international body affiliated with UNESCO, has put forward four important principles, namely: respect and care for the community of life; ecological integrity; social and economic justice; and democracy, nonviolence and peace as the way forward for the future. In order to provide a succinct and relevant curriculum that will enable our future generations, vigorous thought processes needs to be put on to provide our children the skills to acquire new knowledge at all times, to respect human values, dignity and nature as well as act responsibly to sustain peace and harmony.

As curriculum developers delve on current trends globally as well as the emergence of the fourth industrial revolution, sustainable living, and preserving the values and norms of the society, the researcher also studied the statistics of social ills, health index and the deterioration of social norms in the country.

Upon further reflection, it was thought that it would be good to find out from the ground, the perceptions of the common man on the current trends happening globally. The students, who will helm the future of the country, were also asked what their perception is on their areas of study, and what they would prefer to study, as well as their vision of the future world. Then, a snowball sampling method was chosen as the sampling could be very large as it can constitute the total population of adults and students in the country. It was convenient to the researcher to invite acquaintances to answer the questionnaire and ask samples to invite their friends to do so. This will give an indication to the researcher on the perceptions of the general public and whether curriculum developers will need to engage with other ministries, agencies or NGOs to further inform the general public about the latest trends encroaching slowly on their lives.

\section{Research Methodology}

The researcher had the following research questions: 
1. How important is the fourth industrial revolution in curriculum development?

2. What are the essential skills a student needs in the future?

To answer these questions, the researcher sought to find out the perception of the public and interests of students through a survey. The open-ended survey consisted of the following items:

i. on the fourth industrial revolution

ii. how will the fourth industrial revolution will influence our future

iii. the importance of living sustainably

iv. how will education will impact global peace and sustainable development

v. should the fourth industrial revolution as be the key driver of the future curriculum

vi. relevant learning areas our students need to learn for their future

Students also answered questions in the survey that revealed following:

i. the most enjoyable subject(s) in school

ii. why is the subject is enjoyable

iii. which subject is less interesting

iv. why this subject(s) is less interesting

v. what they want to learn in school, given a choice

vi. description of the world they want to live in the future

The sampling method used by the researcher is the virtual snowball sampling. Initial samples came from among researcher's acquaintances who virtually answered the survey. These acquaintances in turn shared the survey instruments shared with their own acquaintances to increase the number of respondents. Snowball sampling is a non-probability sampling method. The researcher did not ask the participants to identify other potential participants but encouraged others to come forward. However, the researcher only managed to get 22 responses from adults and 41 responses from students in 3 weeks.

\section{Findings}

Both the responses given by the adults and students were analysed qualitatively.

\section{Findings from the adult survey}

(i) Out of the 22 respondents only 17 respondents stated their occupation. Most of them are professionals, namely, teachers and a lecturer, an accountant, a radiographer, a retired CEO and a businessman as well as accounts and administrative staff. The following graph depicts the ratio of occupations of the respondents:

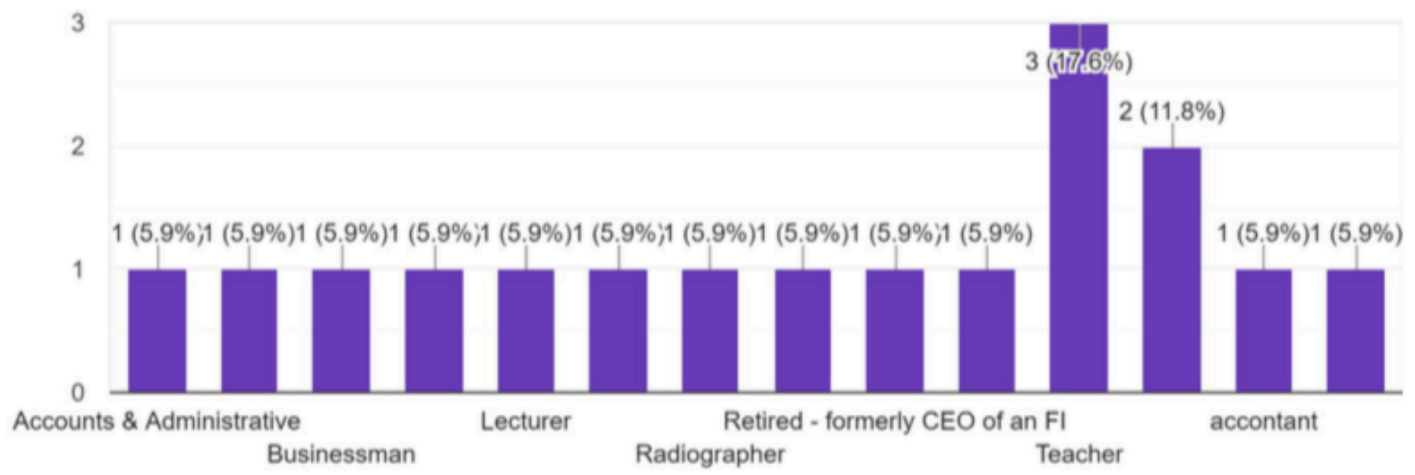

Figure 1. Profile according to occupation.

(ii) Out of the 22 respondents, 21 respondents answered that they are parents. Only one was not. The following is the demography: 


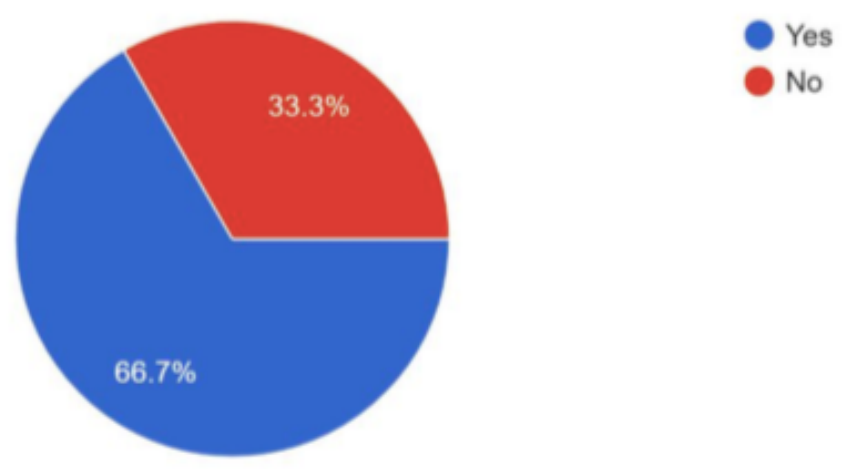

Figure 2. Profile according to parent or not.

(iii) Regarding knowledge about the Fourth Industrial Revolution, three (3) respondents said they do not know anything about it. Most respondents answered that it has to deal with technology: three respondents very aptly said that it the usage of technology at its height; only one respondent said that it has is to do with logistics; one respondent very poignantly said that it is a virtual world; one respondent said that it's artificial intelligence; and another response mentioned that the fourth industrial revolution is all about technology but no place for augmented reality. Below is a few responses of the respondents:

"The fourth industrial revolution is the fusion of technologies and is affecting our daily living as we become dependent on technology for most of our human interaction."

"The fourth industrial revolution is set to change man's life with revolutionary technologies such as big data, augmented reality, autonomous robots, the internet of things, cyber security, additive manufacturing and the cloud. It's going to change the way the future generation will live unimaginable for us today."

"Revolutionary tech such as cyber security, additive manufacturing etc."

"Industrial with integrated AI and machinery with less dependency on manpower."

“Digital Revolution...Artificial intelligence...Data/evidence based learning."

"the future generations"

"Exponential changes and variation in the manner that we function and relate with the adaptation of smart technologies to make decisions autonomously through this technological disruption."

"Fourth Industrial Revolution is what going on now. This industrial revolution is happening because of the development in internet technology. We are so connected to each and other and the world has no boundaries."

A well reflected response is:

"A way to describe the blurring of boundaries between the physical, digital and biological world."

Only four respondents were unaware of the fourth industrial revolution. Most of the respondents were informed and could give the definition according to their own understanding.

(ii) Next, the respondents were required to give their views on how the Fourth Industrial Revolution will influence the future. Two respondents said that they do not know anything about this subject matter. Two responses are "impressively" and "drastically", which clearly stipulates that they are impressed with technological advancement and how it will affect us drastically. 
(a) Most responses were positive on the influence of the Fourth Industrial revolution specifically namely for the younger generation. Some of the responses are:

"I guess with the fourth industrial revolution, it may help younger generation to succeed and penetrate in today's competitive world through networking, etc."

"The next generation with our more tech savvy knowledge."

"It's going to change the way the future generation will live."

(b) Some respondents shared the impact it already has currently and the expectations in the future. Their responses are:

"It already has a major influence at our current moment and is expected to be even more advanced in the future."

"Cashless generation where most things can be obtained at the tips of the finger via internet quick and fast information and processing."

"Greatly, through increase in computing power. Efficiency and productivity."

"Improves efficiency and decision making, organizations become "smarter" using available data to make precise informed decisions, enhances productivity and in turn supply chains are enhanced while the whole eco system improves if developed well and utilized effectively."

"There will be certain fields of work which will be effected. For example the traditional business where needs customers to drive, park and walk to do shopping. It is already being replaced with online shopping. Using online platform, customers can buy products from any part of the world."

(c) Five respondents shared the effects of the Fourth Industrial Revolution in future:

"Jobs will be scarce for low skilled jobs unless there is an effort to retrain them into specific jobs required."

"People will depend more on technology than on their brains."

"Humans will be slaves to technology (AI). Most assembly, laborious, routine, and single instruction or one way activity e.g. in or out, yes or no, even simple accounting and admin will be taken over by technology, which could be between 30 to $40 \%$ of the jobs. Thus the future will depend on the ability to think better, thinking skills will then create the needs for humans or AI will overtake humans."

"Our perception, the way we live, works and how wisely we applies in our life."

"Every things dealing with technologies."

From the responses given, it is clear that most of the respondents were aware of the influence of the fourth industrial revolution in future. They were able to give both the positive and negative impact of the technological revolution; a good insight indeed.

(v) The fifth item in the survey, asked participants on the importance of living sustainably.

Twenty ( 20 ) responses obtained for this question, agreed that it is important to live sustainably in order to have a good quality of life as "resources are getting scarce and with global warming creeping in , ", we need to ensure "we don't run out of resources and also we don't damage or affect our environment." All respondents understood the need of living sustainably in order to secure a promising future for children for the good of humanity so that our resources will not run out and we are able to reduce wastage. At least four respondents see the need for survival as the need is greater now than ever before since our resources are getting scarce and preserving the environment is important for personal growth and peace in an eco-friendly planet. 
Three respondents saw the need to equip themselves with knowledge, skills, attitudes and values and to be able to apply them in life in creatively and innovatively manners in order to keep on track in our fast-paced environment with the advancement of technology.

Some responses are recorded here:

"Sustainability is important for having a good environmental quality in order for us to have healthy communities to live in, with clean air, clean and unpolluted water sources, lots of natural resources, and a non-toxic and pollution - free environment."

"It can re - shape our social, cultural, economic and individual lives besides offering huge potential to transform and realign our economies and societies."

"I guess consumerism already went overboard. People are so consumed on buying that they forget about our landfills, which are mounting with garbage. We need to buy what we need and think of how to dispose unwanted things without further damaging Mother Nature."

"For humans to survive we must live sustainably, but it cannot and will not happen, because humans are individual, and always want to be a leader and to survive better than the other"

All respondents agreed that we need to live sustainably and three respondents in particular saw the need to equip children with the necessary skills to live sustainably and tap on technology to do so.

(vi) The next survey item, sought to get responses on the impact of education on global peace and sustainable development. Most respondents said that education is the key to global peace and sustainability and this should start from the young by instilling moral values e and ethics. Educating children on values such as tolerance, love and teaching them about their rights as well as instilling and inculcating the desire for peace from an early age. Education used as a means to teach about environment and the importance of living sustainably by empowering learners to improve the quality of life through projects in school that promote the importance of global peace and sustainable living creates the right mind- set through character building.

One respondent had a very interesting view, which was connected to the environment and human development as follows:

"Education is key for all human development, be it for good motives or bad. To learn and relearn any skill, knowledge and updating our core values makes us as human unique among all other creatures. Even animals with lower thinking capacity learns how to hunt, play, kill and etc. Humans who are born with better thinking capacity can learn and do much more. We are able to learn from history that war, famine, pestilence and many other life threatening events are bad for us and in learning this we should strive to educate ourselves, our children and their future successors constantly for peace and equality for all human race. As Ghandi says "An eye for an eye and the world goes blind."

One respondent actually connected the need to live sustainably with the need to tap on the facilities of modern technology:

"Smart technology and the use of AI can be used to address the unintended environmental and social consequences of change. Use of data, development of better policy framework, generate better innovation to improve competitiveness. Example the autonomous vehicle that can safe lives as it can be a much safer way to drive, less emission of carbon, improved quality of life."

All respondents agreed that education is the key to global peace and sustainable development. One respondent urged that in order to live sustainably, the future generations need to tap on technology to improve the quality of life and to find the balance which is much needed on our planet.

(vii) The next item looked at the possibility of the Fourth Industrial Revolution being the key driver for the future curriculum. Eleven respondents agreed that it should be the key driver of the future curriculum, stating that it will help our future generation in securing jobs that are in-on demand. Most respondents agreed that education on technology and data will help our future generation to make informed decisions but they must be equipped with ethics and informed of the pros 
and cons of the cyber world. One respondent also noted that this will help in saving our environment and sustainably developing it for the future. One interesting response is:

"Definitely - to meet the demands of change, the whole education and training systems need to be adapted to better prepare our children for strategic and critical thinking skills so that they are able to compete, remain relevant and have the flexibility to adapt and improvise at the workplace using technology, smart systems to manage these dramatic shifts."

Four respondents did not want the Fourth Industrial Revolution to be the key driver in the future curriculum. The responses of two respondents are included here:

"No, it should not be...technology is not the only way forward, we need to go back to basics and teach our children about nature and the importance of all creation on this earth and that our survival as a human race depends on the survival of all creation on this earth and we need to sustain it all."

"No, as it only breeds dependency on all things that has a high technological innovation."

Most respondents viewed the industrial revolution as relevant and should be the driver of change, yet the key ingredient needed is education to better prepare our younger generation on the adverse impact of technology, the transformation it will bring in human lives and for human beings to be masters of it by making informed decisions. As such, the whole education system needs to be viewed in a different light by adapting strategic training for educators to equip our children with relevant soft skills.

(viii) Finally, the respondents were required to list the relevant learning areas (knowledge and skills) our students will need to learn for their future. The responses could be themed according to STEM education, Values and 21st Century Skills.

(a) Among the learning areas mentioned pertaining to values education is character building, care for the environment and sustaining it, managing waste, inculcating civic consciousness as well as empathy and understanding of all creatures including economic and social sustainability.

(b) As for STEM, respondents listed maths and science education, with an emphasis on technology such as Artificial Intelligence, IT software and hardware, Programming, Systems Analysis and Engineering.

(c) Some respondents felt that our students need 21s t century skills, i.e. Digital Literacy, Emotional Intelligence, Critical Thinking and Problem Solving, Entrepreneurship, Assessing and Analysing Information, Knowledge of Collaboration Across Networks and Leading by Influence, Agility and Adaptability, Effective Oral and Written Communication.

All respondents gave important insights as to the relevant learning areas that need s to be included in the future curriculum. Values education, STEM and $21 \mathrm{~s}$ t century skills are viewed as important for a happier and sustainable future.

\section{Findings from the student survey}

The student survey distributed using the snowball method obtained 39 responses. The age range of the respondents was 13 to 23 years old. The students who responded hailed from the government schools, international or private schools and students at colleges/universities. The pie chart below depicts the ratio: 


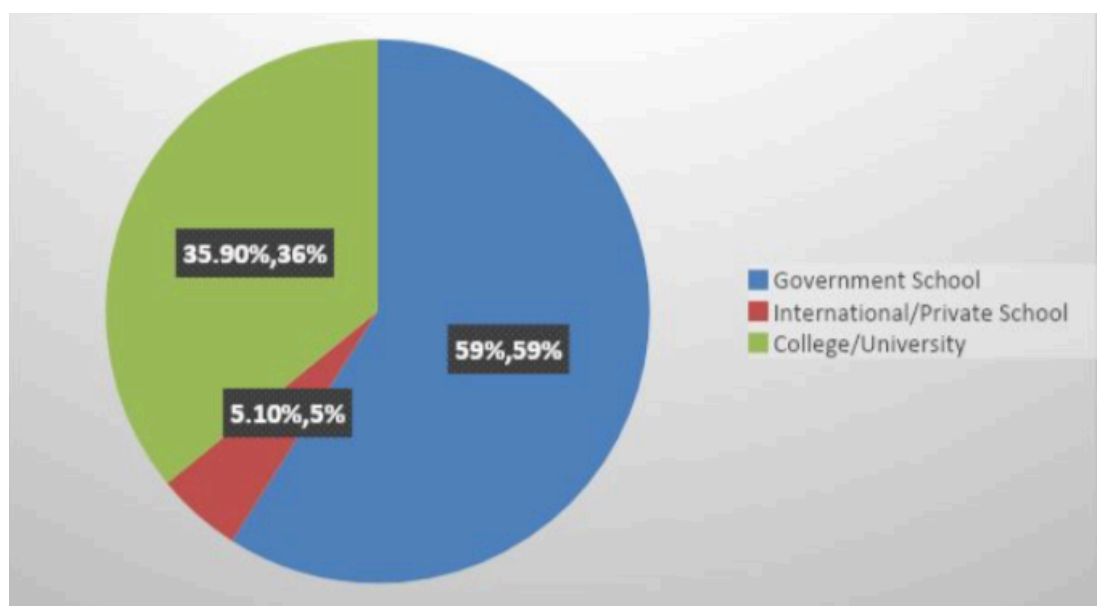

Figure 3. Ratio according to school.

(i) Most Enjoyable Subject(s) in School - Thirteen respondents said that they enjoyed science subjects, which is inclusive of biology, physics and chemistry. Four respondents enjoyed studying mathematics. Two respondents enjoyed studying Physical Education and sports. The rest were more inclined to enjoy social sciences such as Art, English, History and Islamic Education. One student s liked all main subjects and another enjoyed most all the subjects offered in school.

(ii) Reason for Answers in (i) - The responses of the students on why they enjoyed science based subjects are: it contains experiments, feeds their curiosity, they could learn more about living things and it was fun to explore. Students who enjoyed mathematics, said: it was fun if one understands the concept. All other responses related to the teaching method said that the teacher engaged them in fun, inspiring and interesting ways. Students who liked physical activities and sports said that it was more practical.

Respondents mentioned that they were interested in a particular subject as it gave them the opportunity to experiment and could explore with the subject matter learnt which made it fun to learn. Another important factor is the teaching method, which was fun, inspiring and interesting. This implies that the respondents preferred practical things, which can be used in their daily lives.

(iii) Students also responded as to the less interesting subjects, ranging from both the science - based and arts - based subjects including Bahasa Melayu, History, Geography, Physical Education, Health Education, English Language and Moral Education. Science - based subjects that were not interesting for respondents are Maths, Physics and Technology Design. Only one student responded, "In my opinion there is no ' less interesting' subjects because I'm always curious about something and I'm very eager to get to know the answer and why do I get the answer."

(iv) The next item, dealt with the Reasons Why Subjects Were Less Interesting - Among the reasons given involved the teacher factor being boring, less assertive, not friendly and voice not projected well. The teaching methods also were less interesting and concentrated on reading, memorization of facts and getting the answers correct as well as the teacher was unsure of the subject matter. One respondent did not like projects. Some respondents felt that the subject matter was difficult. One respondent pointed out that it was useless to memorize moral values that does not prove whether one is good or bad. And interestingly, one respondent could not see the connection between the subjects learnt in school now with life later on.

The respondents stated very clearly that teaching methods were the contributing factors for them to dislike particular subjects. They also wanted to see a clear link between what they are studying at present and for their future.

(v) What Students Wanted to Learn in School Given a Choice - Subjects ranged from science, sex education, music and art (taught properly), mathematics, drama, law, psychology, cooking, life skills, military strategy, technology, politics, tax payment, emergency learning and astronomy. Four responses were rather interesting as it was from the heart of the respondents: 
"Maybe something that would actually give more benefits in life. Something about how to sharpen my communication skills in both English and Malay, how to help with mental health issues, how to improve myself more as a human, how to prevent suicidal cases and family problems. And maybe showing us more about our culture since Malaysia is multi races country, knowing more about people from the other side like Sabah, Sarawak tradition, traditional arts, lifestyle, traditional dance and music, strengthening our roots from the old times, strengthen bond with others, being open minded, respecting each other, not body shaming or being racist. About people about the world that won't interfere with our religion. Giving more awareness about the earth, about nature. About those who are suffering and how to help them at a young age. About how to make life more comfortable how to move forward this country without destroying mother nature or starting conflicts with others and many more important things that we should learn at a very young age."

"Music...properly taught, art again properly taught.... how to draw, paint...step - by - step guide, ...photography, creative arts like origami, any sport of my choice.... where I am given equal opportunity to try it out instead of being chosen by the teacher."

"More about the things that surround us as well as our environment on a larger scale. I would also like to study useful skills such as those taught thought in the living skills subject that ended after form $3 . "$

"I would love to continue learning and training for basketball with a team because my school does not have a girls' basketball team and that really let me down when I first entered secondary school."

(vi) The Future World that They Would Want to Live In. Most of the respondents wanted a more secure world with the right values, a world where peace dominates, a clean, harmonious world with environmentally aware, where there is health and happiness, self-discipline as well as balanced politics, and a simple and minimalist lifestyle. They want a world without violence and with personal security as well as freedom. Some responses were rather extreme such as military dictatorship and a world without humans. Three respondents wanted a successful life based on being smart, strong, rich and wealthy. One respondent wanted to live in a $1 \mathrm{~s} t$ world country with a stable economy and high standard of living. Below are some responses, which are worth sharing:

"An improved world where everyone would help each other out, a world to move forward without destroying the earth, a world that is less greedy and selfish, a world where money is used to help each other out not only for personal stuff that does not give any benefits. A world where we understand and respect each other."

"A world without war and abuse. A world with more consideration towards environmental pollution. A world full of more open-minded people who can live together without discrimination. A world without cockroaches. A world with no famine or poverty."

"The world that I will like to live in future is to be a fashion designer so I can express myself through fashion better than I do today. I hope that I will use my inspirations and personality to create new styles that many will love and I want to help the children in the world that doesn't have a home, family, and the children who got traumatize to give them a home, comfort, healthy food and medication that they can't afford."

"A less stressful world. A world, which produces quality students who actually get to choose a career, which they really enjoy, and benefit the society. A future where exams do not define one's ability. A world where competition is not the goal."

"I want to live in an educated world where violence is minimal and personal security is assured even though our lives would be largely linked to the online world. I would also like to have a balance in nature as well as modern development in the future."

Most respondents wanted to live in a secure and peaceful surroundings and wanted a balance in life.

\section{Discussion on Findings}

Based on the limited responses from the adult survey, 20\% of the respondents did not know anything about the Fourth Industrial Revolution and its influence in the future. The rest of the respondents were aware of the Fourth Industrial Revolution and its influence. All respondents are aware that it is essential to live sustainably for a better future since as resources are getting scar c e and there is a need for an eco-friendly planet to foster peace. In order to forge through the agenda of living sustainably, most 
respondents agreed that education on global peace and sustainable development was essential. One respondent actually saw the need to use technology in order to address environmental and social change that is happening in the world today. Technology should be used for the betterment of man instead of it being destructive to human beings. Most respondents wanted the Fourth Industrial Revolution to be as the key driver of the future curriculum as they want children equipped with the necessary skills for future jobs. However, they were acutely aware that soft skills are the enhancer to educate children to make informed decisions with strategic and critical thinking skills, yet able to compete and have the ability to adapt and improvise. As to the relevant learning areas for our students, adults felt that STEM-based subjects are as important as Values Education and equipping students with 21 st century skills.

Responses from students who participated in the survey were rather interesting. The subjects they enjoyed in school largely depended on their interests; almost half like social science subjects and the other half like science-based subjects. This was largely due to engaging teaching methods employed by teachers as well as students' own curiosity and intrinsic drive for exploration and experiments. Subjects considered less interesting consisted of both science and social science subjects and the reasons given was as teacher's inability to engage students and captivate their interests. If given a choice, students would like to learn things that will be beneficial to them in the future and interests that across all areas of learning. The respondents were well informed and wellread as they want to live in a world which is clean, peaceful and harmonious with a balance in life, politics, self-discipline and a simple lifestyle. The respondents had a good balance between mind and matter.

As curriculum developers, we encounter challenges in finding the right balance in the future design of a curriculum in order to produce citizens who will be able to fit in the chase for job opportunities. Today, we are faced with the emergence of the Fourth Industrial Revolution and the impact it will have in the future. As very consistently pointed out by the respondents of the study, we as human beings are in charge and need to ensure that we are in control at all times. Klaus Schwab further reiterates this, "In the end, it all comes down to people and values. We need to shape a future that works for all of us by putting people first and empowering them. In its most pessimistic, dehumanized form, the Fourth Industrial Revolution may indeed have the potential to "robotize" humanity and thus to deprive us of our heart and soul. But as a complement to the best parts of human nature creativity, empathy, stewardship - it can also lift humanity into a new collective and moral consciousness based on a shared sense of destiny." This is further reiterated by Sharan Burrow, "The challenge is to make the right choices, putting people at the centre and technology at the service of people. ...We can harness technology to create new jobs and we can ensure a just transition to new employment for those whose jobs are at risk ."

\section{Limitations of the Study}

In order to capture larger respondents, future research should employ a purposive sampling method to get feedback from various people with diverse backgrounds, geographical localities and socio-economic status. This will enable the researcher to be informed about the thoughts of different classes of people throughout the country.

\section{Conclusion}

The job of curriculum developers will be rather challenging, as they need to choose learning areas to be taught in schools relevant for the future generation. They can do this by optimizing learning opportunities and empowering children to think and act in various volatile situations in the future. Each child should be equipped to think, act and live a meaningful life with the right values and adhere to sustainable lifestyles for the future of humankind and the planet.

\section{References}

Bokova, I. (2015). Education 2030: Incheon Declaration and Framework for Action for the implementation of Sustainable Development Goal 4. UNESCO. p 12

Burrow, S. (2019). World Economic Forum: It's people, not technology, that will decide the future of work. Retrieved from https://www.weforum.org/agenda/2019/05/people-not-technology-will-decide-the -future-of-work/

Nichols, J. R. (2019). The Future of Learning: 7 skills students will always need by Teach Thought Staff. Retrieved from https://www.teachthought.com/the-future-of-learning/how-to-prepare-student-for 21 st-century-survival/

Marope, M. (2017). In Focus. Paper: Future Competences for Future Generations. Preparing Learners For The Future We Don't Know. Geneva: International Bureau of Education. 
OECD. (2018). The Future of Education and Skills: Education 2030. France: Author.

Schwab, K. (2016). The Fourth Industrial Revolution: what it means, how to respond. Retrieved from https://www.salesforce.com/blog/2018/12/what-is-the-fourth-industrial-revolution-4I R.html 